\title{
Seborrheic dermatitis
}

\author{
Dermatite seborreica
}

\author{
Ana Luisa Sobral Bittencourt Sampaio ${ }^{1}$ \\ Thiago Jeunon de Sousa Vargas ${ }^{3}$ \\ Amanda Pedreira Nunes ${ }^{5}$
}

\author{
Ângela Cristina Akel Mameri ${ }^{2}$ \\ Marcia Ramos-e-Silva ${ }^{4}$ \\ Sueli Coelho da Silva Carneiro ${ }^{6}$
}

\begin{abstract}
Seborrheic dermatitis is a chronic relapsing erythematous scaly skin disease, the prevalence of which is around 1 to $3 \%$ of the general population in the United States. It has two incidence peaks, the first in the first three months of life and the second beginning at puberty and reaching its apex at 40 to 60 years of age. The prevalence of seborrheic dermatitis is higher in HIV-positive individuals and the condition tends to be more intense and refractory to treatment in these patients. Neurological disorders and other chronic diseases are also associated with the onset of seborrheic dermatitis. The currently accepted theory on the pathogenesis of this disease advocates that yeast of Malassezia spp., present on the skin surface of susceptible individuals, leads to a non-immunogenic irritation due to the production of unsaturated fatty acids deposited on the skin surface. This article provides a review of the literature on seborrheic dermatitis, focusing on immunogenetics, the clinical forms of the disease and its treatment. .
\end{abstract}

Keywords: Dermatitis; Dermatitis, seborrheic; Eczema

Resumo: A dermatite seborreica é uma doença eritêmato-escamativa de caráter crônico-recidivante que acomete entre 1 e 3\% da população geral dos Estados Unidos. Possui dois picos de incidência - o primeiro, durante os três primeiros meses de vida, e o segundo, a partir da puberdade, atingindo seu ápice entre os 40 e 60 anos de idade. Os indivíduos HIV positivos têm maior prevalência da doença, que apresenta maior intensidade e tendência à refratariedade ao tratamento. Doenças neurológicas e outras doenças crônicas também estão associadas ao desenvolvimento da dermatite seborreica. Como mecanismo fisiopatogênico, reconhece-se que o fungo Malassezia sp., presente na pele de indivíduos suscetíveis, leve a uma irritação não-imunogênica a partir da produção de metabólitos à base de ácidos graxos insaturados deixados na superfície cutânea. Este artigo faz uma revisão da literatura sobre dermatite seborreica, com ênfase nos aspectos imunogenéticos, formas clínicas e tratamento.

Palavras-chave: Dermatite; Dermatite seborreica; Eczema

Received on 18.11.2010.

Approved by the Advisory Board and accepted for publication on 24.03.2011

Study conducted at the Department of Dermatology, Clementino Fraga Filho Teaching Hospital, Federal University of Rio de Janeiro, Rio de Janeiro, RJ, Brazil. Conflict of interest: None / Conflito de interesse: Nenbum

Financial funding: None / Suporte financeiro: Nenbum

MD. Master's student in Internal Medicine, Medical School, Federal University of Rio de Janeiro, Rio de Janeiro, RJ, Brazil.

Master's degree in Dermatology awarded by the Federal University of Rio de Janeiro. Head of the Dermatology Unit, Clinic of Medical Specialties, Vitória, ES, Brazil. Research Fellowship, Ackerman Academy of Dermatopathology. Physician, Preceptor and Head, Dermatopathology Department, Dermatology Unit, Hospital Federal de Bonsucesso, Rio de Janeiro, RJ, Brazil

$\mathrm{PhD}$ in Dermatology awarded by the Federal University of Rio de Janeiro. Associate Professor and Head, Dermatology Department, Clementino Fraga Filho Teaching Hospital, Federal University of Rio de Janeiro, Rio de Janeiro, RJ, Brazil.

Medical student, School of Medicine, Federal University of Rio de Janeiro, Rio de Janeiro, RJ, Brazil.

$\mathrm{PhD}$ in Dermatology awarded by the Federal University of Rio de Janeiro. Adjunct Professor of Dermatology, School of Medical Sciences, State University of Rio de Janeiro. Collaborating Professor and Dermatologist, Clementino Fraga Filho Teaching Hospital, Federal University of Rio de Janeiro, Rio de Janeiro, RJ, Brazil. 


\section{INTRODUCTION, HISTORY AND EPIDEMIOLOGY}

Seborrheic dermatitis (SD) is a common, chronic inflammatory disease that affects around $1-3 \%$ of the general population in the United States, 3-5\% of patients consisting of young adults. The prevalence of SD in HIV-positive individuals ranges from $20-83 \% .{ }^{1}$ The incidence of the disease has two peaks: one in newborn infants up to three months of age, and the other in adults of around 30-60 years of age. ${ }^{2}$ The bimodal presentation of the disease (at birth and postpuberty) suggests that it may be associated with the sex hormones. Men are affected more often than women in all age groups and there is no preference for any specific ethnic group.

Malassez was the first to describe yeast-like fungal elements detected in flakes from the scalp, probably representative of the disease that would come to be known as SD following its original description by Unna in 1887. ${ }^{3.5}$ In 1952, Leone linked Pityrosporum ovale (later baptized Malassezia spp.) with pityriasis of the scalp, seborrheic eczema and various other squamous dermatoses. ${ }^{6,7}$

In the 1950s, the focus of research on SD was the investigation of its association with vitamin $\mathrm{B} 2$, B6, B12 and biotin deficiency. ${ }^{8.16}$ Nevertheless, up to the present date the association between SD and nutritional deficiencies has yet to be confirmed. ${ }^{17}$ Sudan defended the theory that nicotine acts as a hapten in the physiopathogenesis of SD. ${ }^{18.22}$ Today, recent studies have shown the importance of the role played by Malassezia spp., present in the normal human flora, in the genesis of SD lesions in susceptible patients. ${ }^{17,23-25}$ Its participation was suggested by the fact that the disease responds to treatment with antifungal medication. ${ }^{17}$

In addition to human immunodeficiency virus (HIV) infection, some neurological diseases such as Parkinson's disease also result in a higher incidence of SD, and Parkinson's patients in treatment with levodopa experience an improvement in SD. ${ }^{26-31}$ The higher incidence of SD in patients with Parkinson's disease appears to be related to an increase in male sex hormone secretion and the effects of these hormones on the sebaceous glands rather than on autonomic dysfunction (dysautonomia), as was previously believed. 32 A higher prevalence of SD has also been found in cases of neuroleptic-induced Parkinsonism, in craniosynostosis, in familial amyloidotic polyneuropathy, in traumatic brain injury, traumatic spinal cord injury, cerebrovascular accidents (CVA), epilepsy and in facial nerve paralysis. ${ }^{25,33-38}$ SD has also been described as occurring exclusively on the side affected by paralysis in patients with CVA, following decompression for Chiari type-I malformation or in an area affected by syringomyelia. ${ }^{38-40}$
In 1996, Ercis et al. reported that $30.9 \%$ of individuals with Down syndrome had SD; however, Daneshpazhooh et al. reported a prevalence of only $3 \% .{ }^{41,42}$

Other systemic diseases in which the incidence of SD is higher include acute myocardial infarction, alcoholic pancreatitis and alcoholism. ${ }^{43.47}$

\section{ETIOPATHOGENESIS}

Malassezia spp.

Malassezia spp. is a lipophilic fungus that is part of the flora normally found on the human skin. It was first described in the mid-1840s by Eichsted and Sluyter, who associated it with pityriasis versicolor. In 1853, Robin denominated it Microsporum furfur and in 1874 Malassez described this fungus in flakes taken from the scalp. 3,48

The genus Malassezia was first described by Baillon in 1889 and has taxomonic priority over the genus Pityrosporum used by Sabouraud in 1904 to refer to the same group of microorganisms. The current classification includes the genus Malassezia, which belongs to the family Cryptococcaceae of the class Basidiomycetes. ${ }^{49}$

Malassezia is a dimorphic fungus that is highly pleomorphic. Since its initial classification was based on morphological criteria, it was denominated Pityrosporum ovale (oval yeast cells with a broad budding base) and Pityrosporum orbiculare (round yeast cells with a narrow budding base). Later it was concluded that both forms were morphological variants of the same species. Currently, following evaluation using serological and genetic methods, the genus Malassezia has been divided into seven species: $M$. furfur, M. pachydermatis, M. sympodialis, M. globosa, M. obtusa, M. restricta and M. slooffiae (Table 1). ${ }^{49,50}$

Although Unna described seborrheic dermatitis as a disease in 1887 , it was Malassez who first observed the fungus in flakes taken from the scalp in $\mathbf{1 8 7 4 .}$ 3.5 Later, Moore and Kile linked Malassezia spp. directly to the disease. ${ }^{48}$

Malassezia $s p p$. is associated both with infec-

TABle 1: Taxonomic classification of Malassezia spp

$\begin{array}{ll}\text { Class: } & \text { Basidiomycetes } \\ \text { Family: } & \text { Cryptococcaceae } \\ \text { Genus: } & \text { Malassezia } \\ \text { Species: } & \text { M. pachydermatis } \\ & \text { M. furfur } \\ & \text { M. sympodialis } \\ & \text { M. globosa } \\ & \text { M. obtusa } \\ & \text { M. restricta } \\ & \text { M. slooffiae }\end{array}$


tious diseases in which the microorganism is the direct etiological agent and in inflammatory diseases of multifactorial etiology in which the exaggerated growth of Malassezia spp. functions as a triggering or aggravating factor in susceptible patients. The former group includes pityriasis versicolor, Malassezia (pityrosporum) folliculitis, pneumonia due to Malassezia spp., sepsis associated with deep venous catheterization in patients on total parenteral nutrition and peritonitis in individuals submitted to outpatient peritoneal dialysis. In the latter group, SD is the prime example, together with confluent and reticulated papillomatosis (Gougerot-Carteaud syndrome), psoriasis and atopic dermatitis. ${ }^{51.53}$

Each one of these diseases has various clinical and histological manifestations that cannot be explained by the mere presence of a certain species of Malassezia on the skin, with contributing factors including the individual's immunological and genetic profile. ${ }^{54}$

The exact physiopathology of seborrheic dermatitis is yet to be completely established; however, today the rule is the association of the disease with the presence of Malassezia spp. yeast on the skin of affected individuals. This is known to be present on all human skin but may be present to a greater extent in individuals with SD. ${ }^{55-57}$ Nevertheless, in 1989, Bergbrant and Faergman failed to find any difference in the amount of Malassezia spp. between individuals with SD and healthy controls or between skin with SD lesions and healthy skin. ${ }^{58}$ These findings suggest that there are other pathophysiologic mechanisms associated with an abnormal reaction to Malassezia $s p p$. and that they are not necessarily related to its amount.

In 1984, Bourlond et al. showed that $P$. ovale (i.e. Malassezia spp.) could be found on any flaky surface (SD, actinic keratosis, nevi and viral warts) and that the multiplication of this fungus at these sites makes its demonstration simpler. ${ }^{59}$

Various studies were conducted to define the most prevalent species of Malassezia in SD. Nakabayashi et al. reported having found 35\% of $M$. furfur and 22\% of M. globosa in individuals with SD. ${ }_{60,61}$ Rendic et al. found M. globosa in 67\%, followed by M. furfur and sympodialis. ${ }^{62}$ Gupta and Gaitanis reported a greater amount of $M$. globosa. ${ }^{63,64}$ Tajima was the only author to report $M$. restricta as being the most common. ${ }^{65}$

Nakabayashi and Sei found that children with SD had a greater amount of Malassezia (M. furfur and M. globosa) compared to children without the disease. ${ }^{66}$ Bergbrant considers that the quantity of $P$. ovale (i.e. Malassezia spp.) in the skin is not the determining factor for an inflammatory reaction, but rather the quantity of lipids on the skin surface and the individual's immune response to the presence of the fungus. This investigator also observed the relationship between the disease and hereditariness, seasonality and mental stress and with reduced T-cell function. ${ }^{58}$ ${ }^{67,68}$ To corroborate the evidence that Malassezia spp. contributes to skin inflammation in SD, Plotkin in 1996 and De Angelis in 2007 described the production of a lipase by this fungus that is essential for its growth in vitro and in vivo. ${ }^{69,70}$ The hypothesis would be that the fungus uses lipids from the skin surface to produce unsaturated and saturated fatty acids that, when left in the individual's skin milieu induce an inflammatory response. ${ }^{71,72}$

The sebum in the skin permits the growth of $P$. ovale (i.e. Malassezia) and hence the development of SD. Therefore, maintaining reservoirs of residual sebum (when hygiene is poor, for example) may predispose to the appearance of the disease, as occurs in neuropathic patients. ${ }^{73}$

The fact that SD responds to treatment with antifungal medication represents concrete evidence of the association between Malassezia and SD. ${ }^{72,74,75}$

In 2007, Dawson argued that the development of SD depends on three factors: sebum production, the metabolism of Malassezia and the individual's susceptibility. ${ }^{76}$

\section{HISTOPATHOLOGY}

The histopathology of SD depends on the clinical stage of the disease. In the acute and sub-acute phases, an inflammatory infiltrate composed principally of lymphocytes and histiocytes is found in association with mild to moderate spongiosis and psoriasiform hyperplasia associated with parakeratosis around follicular ostia ("shoulder parakeratosis") (Figures 1 and 2). On the other hand, during the chronic phase, in addition to the above-mentioned findings, there is marked psoriasiform hyperplasia with dilatation of the capillaries and venules of the superficial plexus, which makes it very similar to psoriasis. ${ }^{77}$ In psoriasis vulgaris, the histopathology findings are similar except for the spongiosis. ${ }^{78}$

\section{IMMUNOGENETICS}

Faergemann described an increase in the number of natural killer (NK) T cells, as well as low titers of IgG class antibodies in patients with SD compared to controls. Lymphocyte activity decreases in individuals with SD when in contact with Malassezia spp. and there is a reduction in IL-2 and IFN- $\gamma$ and an increase in IL-10 production. ${ }^{79}$ In a subsequent study, the same author reported a greater number of NK1+ and CD16+ cells associated with complement activation in SD lesions compared to healthy skin in the 


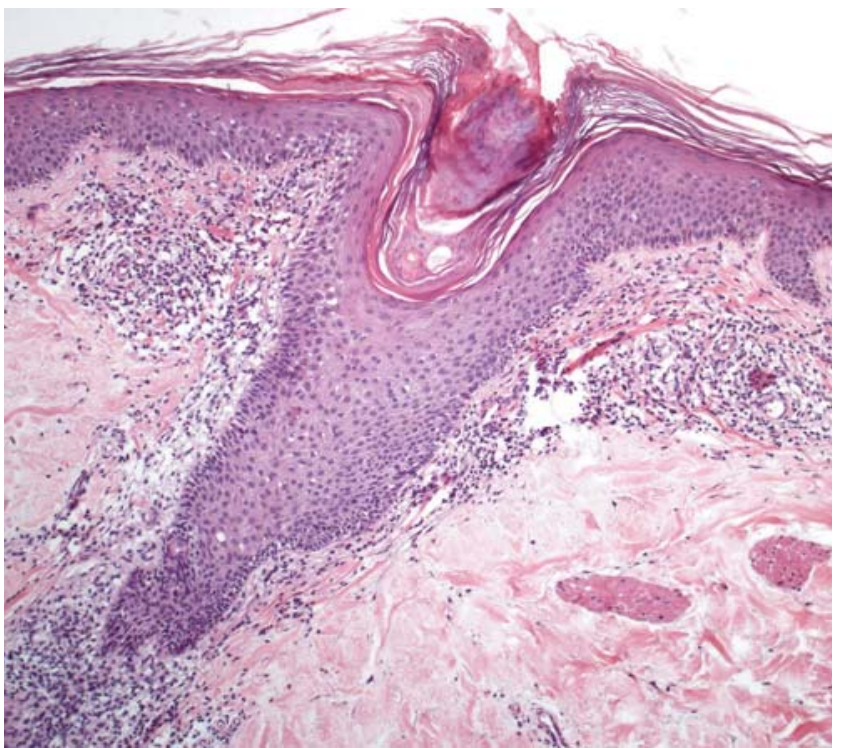

Figure 1: Mild spongiosis in infundibulum with scale crust (shoulder parakeratosis) in the follicular ostium and formation of a keratinous plug. Dermis presenting mononuclear inflammatory infiltrate. (HE, 100x original magnification)

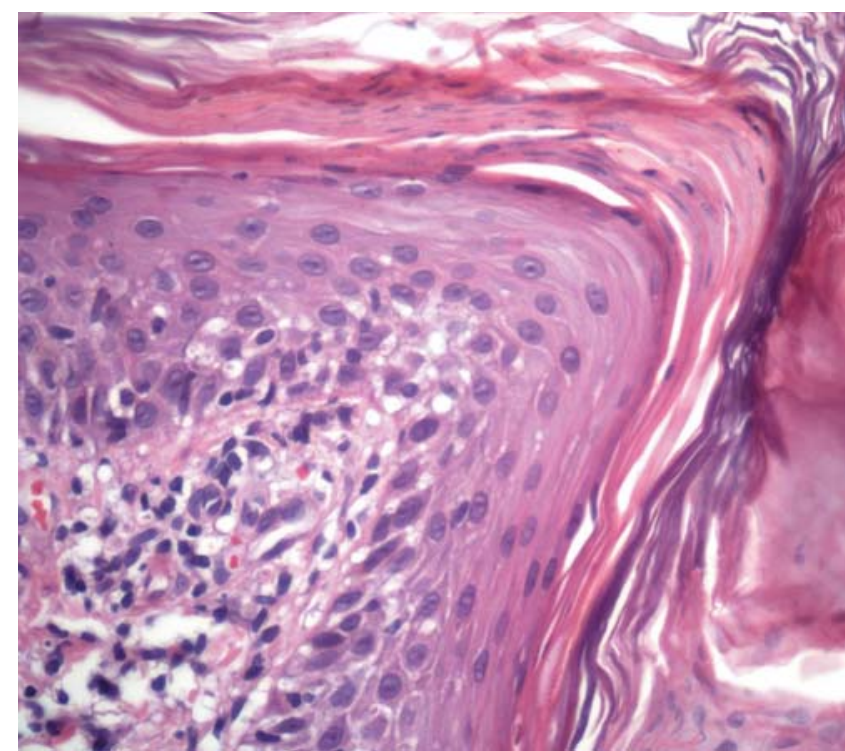

FIGURE 2: Detailed image of spongiosis in the infundibulum and scale crust (shoulder parakeratosis) in the follicular ostium. Dermis presenting mononuclear inflammatory infiltrate. (HE, 400x original magnification)

same patients or to the skin of individuals without SD, suggesting the presence of an intense, irritative, nonallergic immune response. ${ }^{80}$

In 1988, Parry and Shape failed to find either circulating antibodies against the fungus or systemic sensitivity, leading to the conclusion that there is no change in humoral response to Malassezia spp. but rather an alteration in cellular immune response. ${ }^{81,82}$ Neuber et al. also reported an alteration in cellular immunity in SD. ${ }^{83}$
Watanabe et al. showed that $M$. furfur does not lead to cytokine production by the keratinocytes, whereas this occurs with the other species of Malassezia. Furthermore, these investigators reported that, depending on the species of Malassezia, production of a certain profile of inflammatory interleukins is stimulated, thus characterizing a different disease. For example, when IL-8 is produced, neutrophils are attracted, manifested clinically in the form of Malassezia folliculitis; likewise, lack of production of monocyte chemotactic protein-1 (MCP-1) clinically determines SD. ${ }^{84}$

No increase was found in the production of anti-Malassezia antibodies (IgM and IgG) in patients with SD. This observation was significant in patients with atopic dermatitis and suggests that there is no anti-Malassezia $s p p$. humoral immune response in SD. ${ }^{79,82,85}$

Passi et al. found decreased serum levels of vitamin E, polyunsaturated fatty acids and erythrocyte glutathione peroxidase activity in patients with SD (both in HIV-positive and HIV-negative individuals) and suggested an association between these findings and the pathogenesis of the disease. ${ }^{86}$

In 2007, Ianosi described the inflammatory infiltrate in SD: poor in CD20+ and rich in CD45Ro. ${ }^{87}$

\section{Human leukocyte antigen (HLA) system}

Although there is evidence that hereditariness is the predisposing factor for $\mathrm{SD}$, the only description of HLA typing in patients with seborrheic dermatitis was published by Tsuji in 1976. This investigator typified HLA in patients with psoriasis vulgaris, palmoplantar pustulosis, seborrheic dermatitis and in healthy individuals. He found an increase in the frequency of HLAA1 and HLA-BW37 in patients with psoriasis vulgaris and an increase in the frequency of HLA-AW30 and/or AW31 and HLA-B12 in seborrheic dermatitis. ${ }^{88}$ The research group represented by these authors is conducting studies to clarify the role of immunogenetics in SD.

\section{CLINICAL DIAGNOSIS}

SD has distinct characteristics depending on the age group affected: the pediatric form is self-limiting, whereas in adults the disease is chronic. ${ }^{89}$ The lesions consist of erythematous, flaking plaques of varying extents and degrees of intensity.

In infancy, $S D$ is more prevalent in the first three months of life (10\% in boys and $9.5 \%$ in girls), with flaking on the scalp being the most common clinical manifestation (42\%). ${ }^{90}$ It is characterized by the appearance of yellowish adherent scales of varying extent that appear shortly after birth. They may also develop on the face and in the body folds such as in 
the retroauricular region, neck, axillae and inguinal region. The child with SD may present with a rare, generalized form that is often associated with immunodeficiency. ${ }^{17}$

In adults, SD is a chronic, relapsing dermatosis that may range from a mild to moderate erythema to papular, exudative and/or squamous lesions with periods of exacerbation related to stress or sleep deprivation. ${ }^{17,91}$

The areas affected and the prevalence of each one of these areas are as follows: face (87.7\%), scalp (70.3\%), chest (26.8\%), lower limbs (2.3\%), upper limbs (1.3\%) and other sites (5.4\%) such as body folds (Figure 3). ${ }^{92}$ The lesions consist of macules or thin plaques with well-defined borders that may be pink, light yellow or erythematous, with fine, dry white or even moist or oily, yellowish scales. They may be limited to small areas of the body; however, there have been reports of generalized forms and even of erythroderma. ${ }^{93-96}$ The presence of pruritus is variable. The principal complicating factor in the lesions is secondary bacterial infection, which increases the erythema and exudate, local discomfort and lymphadenomegaly close to affected areas.

The lesions develop principally on areas in which sebum production is high such as the scalp, face, external ear, retroauricular region and presternal area, eyelids and body folds (Figures 4-10).

The lesions on the scalp range from a mild desquamation (pityriasis simplex capillitii) to honey-colored crusts completely affixed to the scalp and hair,

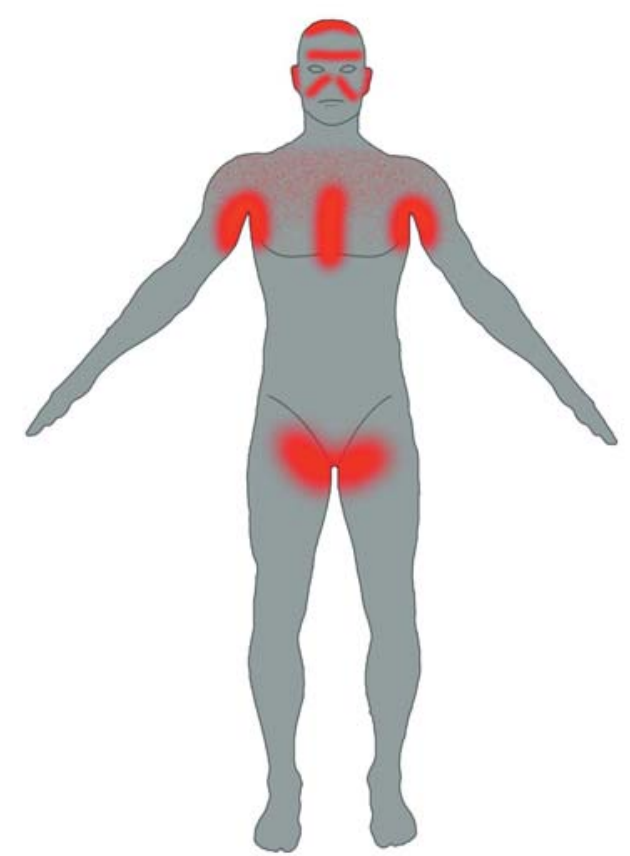

Figure 3: Body sites affected by seborrheic dermatitis which may or may not provoke areas of alopecia (pseudo tinea amiantacea). On the face, involvement of the glabella and malar regions, the nasolabial folds and the eyebrows is characteristic. Involvement of the eyelids leads to blepharitis. In men, the beard area may also be affected with SD lesions. In the body folds (axillae, umbilicus, inguinal, inframammary and anogenital regions), lesions may acquire a moist, macerated appearance with erythema at the base and around the lesions. They may progress with fissures and secondary infection. In the presternal area, lesions may be more erythematous and scaly with arciform patterns (psoriasiform) on the borders of the lesion or in the shape of flower petals (scales over the lesion).

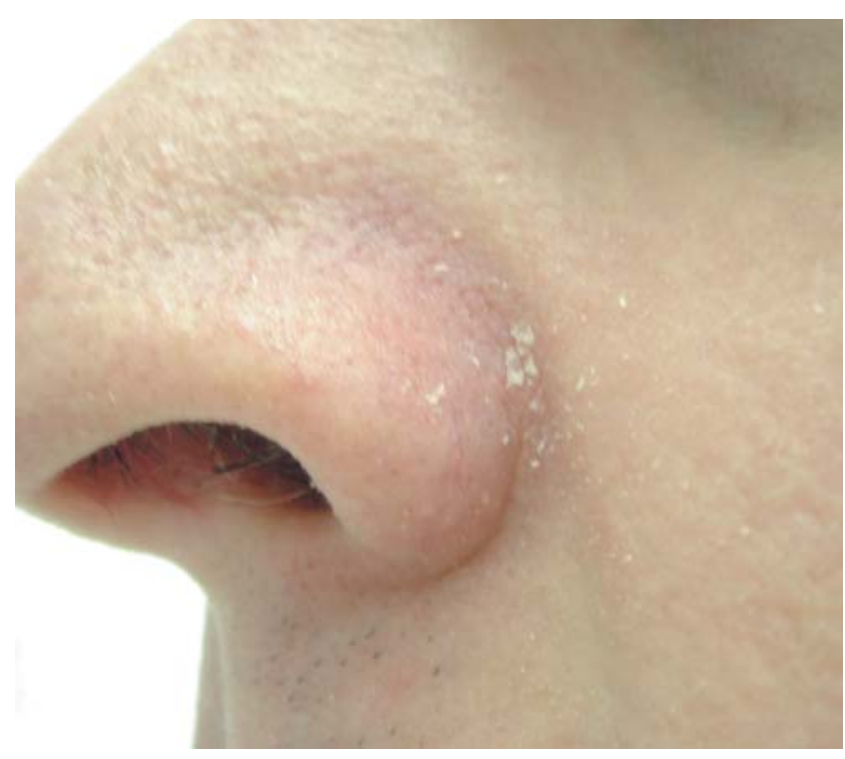

FIGURE 4: Mild erythema and desquamation in the nasolabial fold

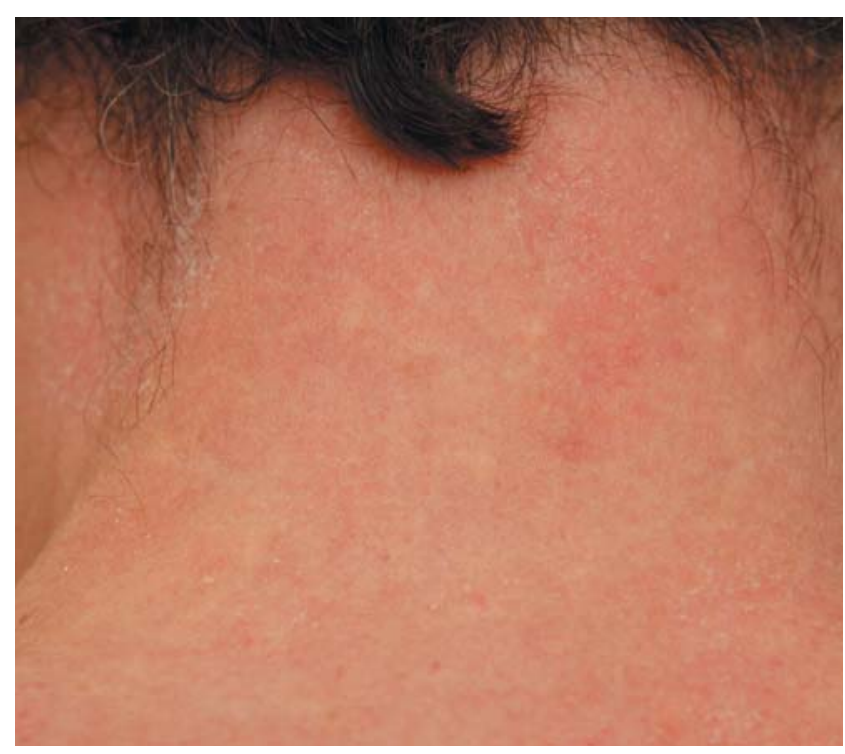

FigURE 5: Diffused erythema and desquamation on the back of the neck 


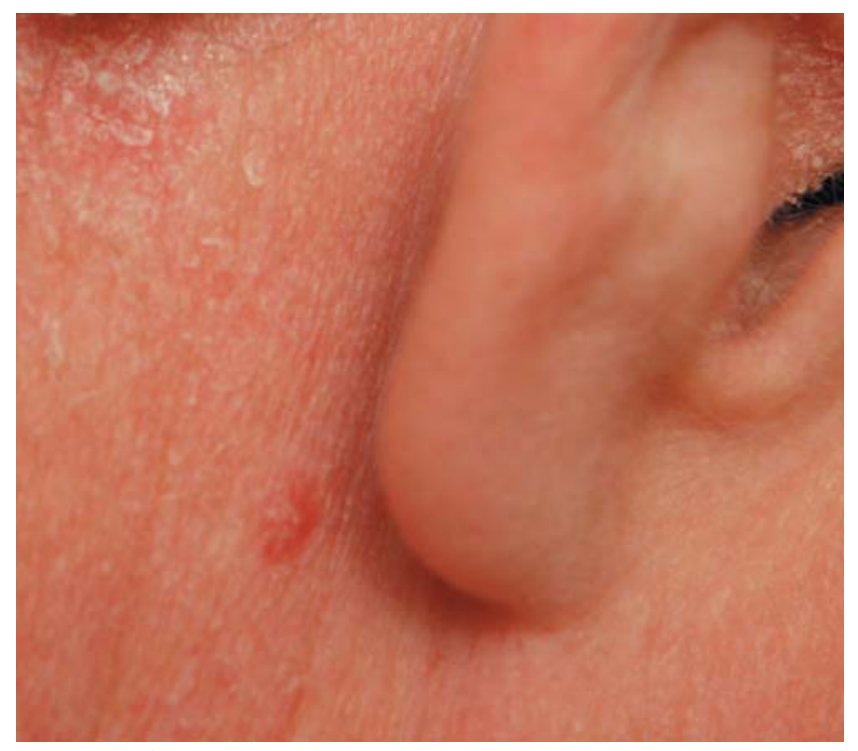

FiguRE 6: Lesions affecting the external ear and retroauricular region. Dressing covering the site of previous biopsy

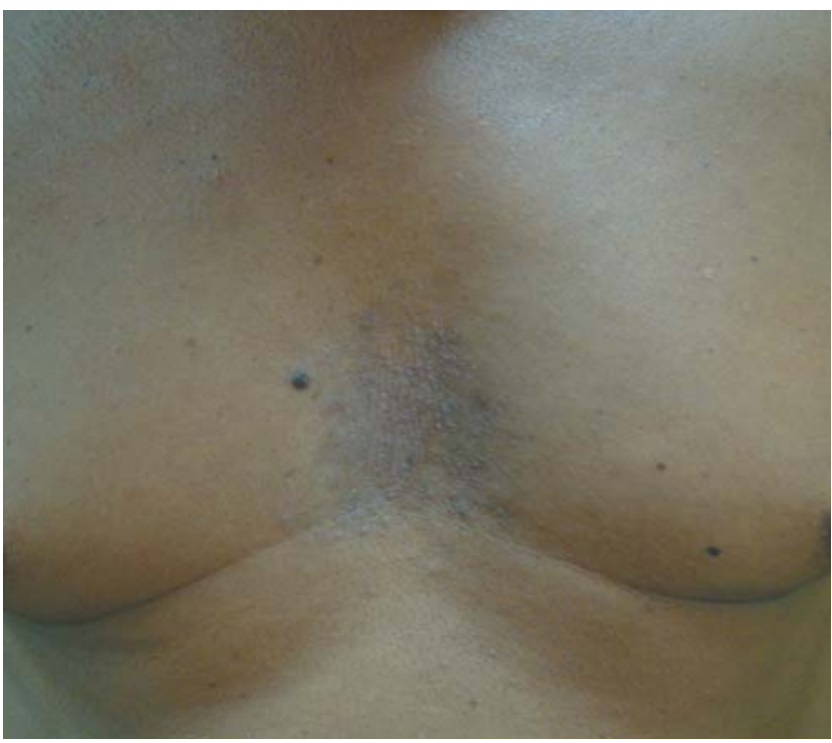

Figure 7 - Papular, scaling lesions on the presternal region

\section{DIFFERENTIAL DIAGNOSIS}

Differential diagnoses in cases of SD include psoriasis, atopic dermatitis (principally in the pediatric form of SD), tinea capitis, cutaneous lymphoma and cutaneous Langerhans cell histiocytosis. ${ }^{17}$ There is also a type of dermatitis that is similar to $\mathrm{SD}$ and is induced by drugs (gold, buspirone, chlorpromazine, ethionamide, griseofulvin, haloperidol, IL-2, interferon- $\alpha$, lithium, methoxsalen, methyldopa, phenothiazines, psoralens and stanozolol, among others) or by nutritional deficiency (riboflavin, pyridoxine, niacin and zinc). ${ }^{97,98}$

Infantile $\mathrm{SD}$ is similar to atopic dermatitis (AD);

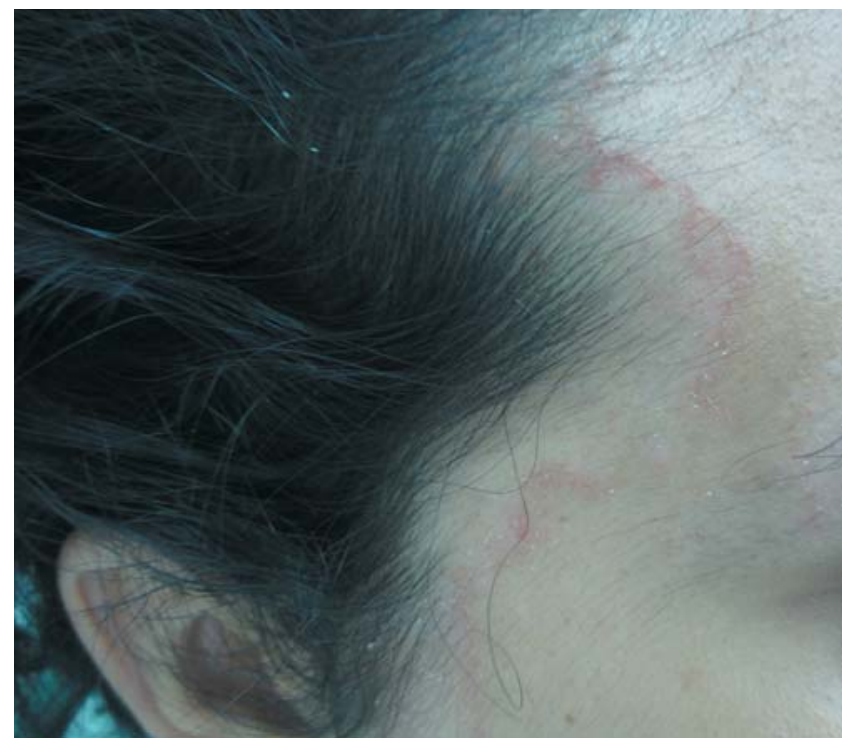

FIGURE 8: Ring-shaped, erythematous scaling plaque on the temporal region along the hairline

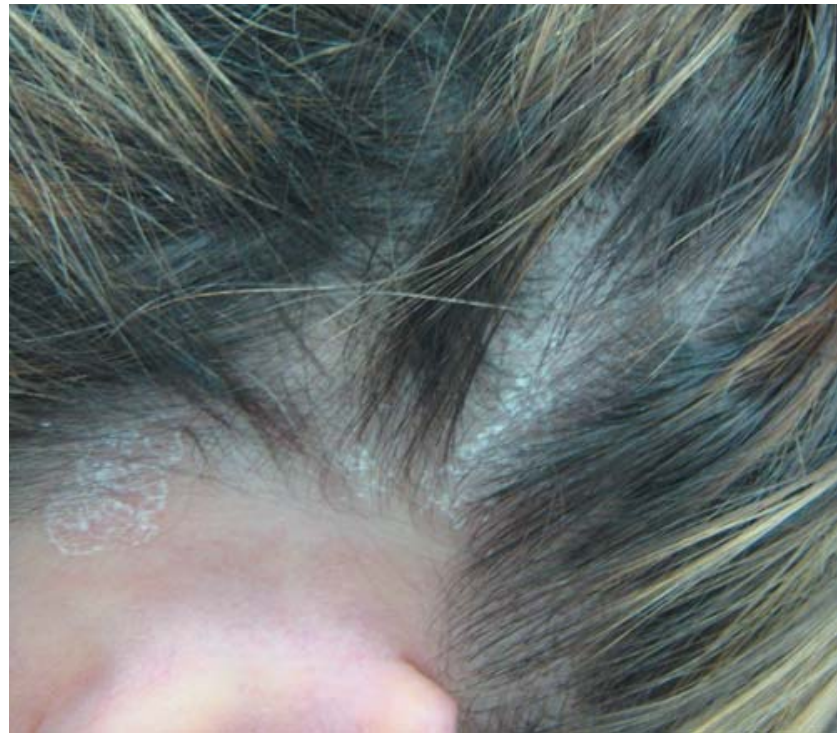

Figure 9: Typical desquamation on scalp

however, the sites affected (body folds in the case of $\mathrm{SD}$ and extensor surfaces in $\mathrm{AD}$ ) and the absence of pruritus in SD are factors that differentiate the two conditions. Diaper dermatitis does not affect the body folds, whereas SD affects these areas predominantly. Infantile psoriasis is very similar to SD in this age group and it is almost impossible to differentiate between the two conditions.

There is a debate on the difference between SD of the scalp and a disorder referred to as pityriasis simplex capillitii, a mild, dry, desquamation of the scalp that may merely represent a physiological shedding of 


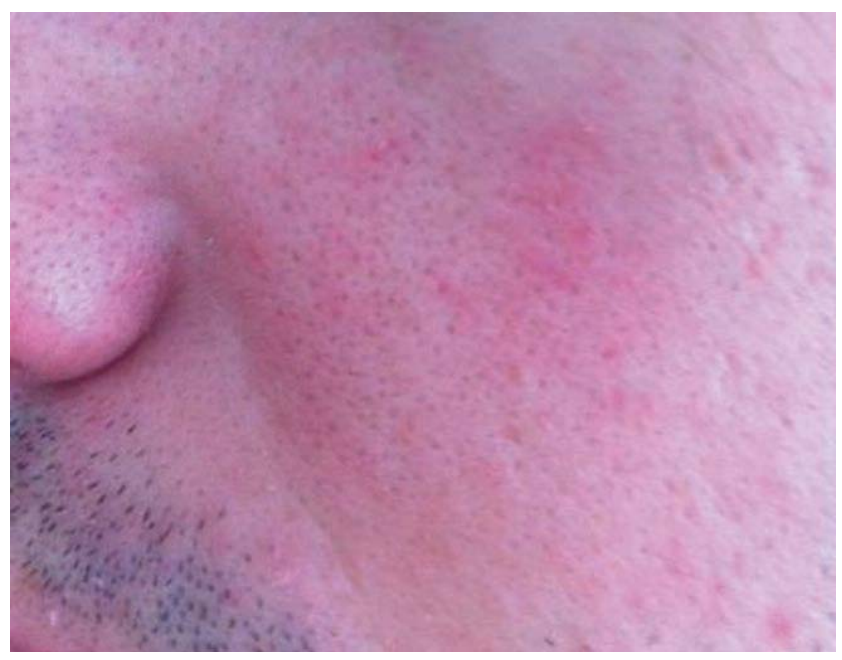

FIGURE 10: Characteristic erythematous papules of mild seborrheic dermatitis

the stratum corneum or may be a consequence of the excess use of cosmetics such as hair creams or gels. It is also difficult to distinguish between SD and psoriasis of the scalp. The psoriasis lesions are better-defined, thick plaques with dry white flakes. ${ }^{89}$

On the face, SD lesions are similar to those of acute cutaneous lupus erythematosus (bilateral malar eruption) and of rosacea. In the body folds, they should be differentiated from primary irritant contact dermatitis, from inverse psoriasis, dermatophytosis and erythrasma. Langerhans cell histiocytosis may affect the body folds and the scalp, leading to a clinical appearance that is very similar to that of $\mathrm{SD}$; however, the presence of a purpuric component in the lesions renders the former diagnosis more likely. ${ }^{89}$

\section{SEBORRHEIC DERMATITIS AND HIV}

Eisenstat first described the association of SD and acquired immunodeficiency syndrome (AIDS) in 1984. The prevalence of SD in HIV-positive individuals differs according to various authors. For Soeprono et al., $85 \%$ of individuals with AIDS have SD, whereas Berger reported this figure as $36 \%$, Goodman as $32 \%$ and Blanes et al. as $31 \%$ of patients. ${ }^{92-102}$

Malassezia spp. is also involved in the development of the disease. No increase was found in the amount of $P$. ovale (i.e. Malassezia spp.) on the skin surface when individuals with and without AIDS were compared; however, it would appear that the specific subtype of Malassezia spp. present is more important than the extent of the fungus on the skin surface. ${ }^{103,104}$ Rincón et al. reported a predominance of Malassezia globosa in individuals with pityriasis versicolor (67\%) and in HIV-positive patients with SD (85\%), whereas in HIV-negative SD patients the predominant Malassezia species were $M$. furfur and M. restricta, found in $72 \%$ and $26 \%$ of cases, respectively. ${ }^{105}$
Vidal et al. described the lipid profile of the skin of individuals with AIDS as being different from that of individuals without AIDS; however, these investigators did not determine its relationship with the development of SD. ${ }^{106}$ Passi et al. (1991) reported that the total lipid concentration on the skin surface of HIVpositive and HIV-negative patients with seborrheic dermatitis was similar; however, they reported significant alterations in the lipid fractions of HIV-positive patients including a reduction in squalene and an increase in cholesterol and in cholesterol esters. ${ }^{107}$

SD usually occurs in HIV-positive individuals with a CD4+ T-lymphocyte count of 200-500 and is considered an early skin manifestation of AIDS. ${ }^{108}$ Response to antiretroviral treatment is variable and there have been conflicting reports in the literature: some investigators reported an improvement in SD with the initiation of antiretroviral treatment, while others reported aggravation. ${ }^{109,110}$ Furthermore, there have been reports of aggravation during immune reconstitution inflammatory syndrome and reports that antiretroviral treatment does not alter the prevalence or the course of SD. ${ }^{111,112}$

With respect to histopathology, the findings of SD in HIV-positive patients are similar to those found in HIV-negative patients; however, there appears to be greater follicular involvement in the lesions and more plasmocytes in the inflammatory infiltrate in the HIVpositive patients. ${ }^{17,78,101}$

The clinical appearance of SD is typical, affecting areas rich in sebaceous glands and accompanied or not by pruritus. Children with AIDS also have SD. 113 Nevertheless, if the disease appears for the first time or if there is an exacerbation in an HIV-positive individual who, prior to that, had a mild form of the disease, this may indicate seroconversion from the latent phase to the symptomatic phase. ${ }^{104}$ SD may also be more extensive, more intense and refractory to conventional treatment. These cases tend to benefit from the use of oral antifungal agents or the association of drugs with antifungal agents and topical, lowpotency corticosteroids. ${ }^{114}$ There have also been reports of a clinical improvement with the use of antiretroviral drugs. ${ }^{109,115}$

\section{TREATMENT}

Since this is a chronic inflammatory disease that probably occurs in response to the presence of a fungus (Malassezia spp.) on the skin and to its metabolism through the use of lipids from the skin, the objective of treatment consists in controlling the inflammation, proliferation of the microorganism and the oiliness. Various classes of medication are used; therefore, the therapeutic arsenal for the control of SD is extensive. The first rule is to inform the patients with 
respect to the chronic, relapsing nature of the disease. The individual who is aware of the course of the disease gains greater confidence and complies better with treatment. ${ }^{116}$

According to a survey conducted by Peyri et al., the most commonly used drugs are the corticosteroids $(59.9 \%)$ and imidazole-based antifungals (35.1\%). Moisturizing creams were also reported in $30.7 \%$ of cases, topical calcineurin inhibitors in $27.2 \%$ and other pharmacological treatments such as systemic antihistamines and a variety of natural therapies in $5.1 \% .{ }^{92}$

The following paragraph lists the drugs used for the treatment of SD, grouped according to the therapeutic modalities:

Soaps: the types of soaps available include those containing ketoconazole $2 \%$ and sulfur with or without salicylic acid. Tea tree (Melaleuca alternifolia) oil-based soaps have proven effective against SD due to their antifungal potential. ${ }^{117}$ They are also available in the form of shampoos.

Shampoos: the shampoos used for the control of SD are classified in accordance with their effect. Antiproliferative: Based on coal tar and its derivatives, they are antimitotic and cytostatic, causing a reduction in cell division in the epidermis, which is the cause of scale formation. Other examples are selenium sulfate ( 1 and $2.5 \%$ ) and zinc pyrithione ( 1 and $2 \%$ ). Antifungals based on ketoconazole $2 \%$, ciclopirox $1 \%$ and also selenium sulfide and zinc pyrithione. Keratolytics: based on salicylic acid (2-6\%) with or without sulfur $(2-5 \%)$ promote removal of the adherent flakes. Anti-inflammatories: containing corticosteroids (clobetasol propionate), they exert effects similar to those used in the form of hair tonics. ${ }^{118}$ The combination of various classes of drugs in one single product or the use of rotational therapy are the most effective options and the ones that result in fewer recurrences.

\section{Topical Medication:}

Topical antifungal preparations: ketoconazole, as well as other imidazole derivatives, and antifungal agents of other pharmacological classes such as ciclopirox, all of which can be used in the form of lotions, creams or ointments, are always used whenever there is a recurrence of SD. Although the anti-androgenic effect of these drugs remains a subject of debate, the dose required for this effect to occur is very high (equivalent to $600-800 \mathrm{mg} /$ day of oral ketoconazole) and it is improbable that this dose would be reached with topical treatment. ${ }^{119}$ On the other hand, there are indications that some antifungals have anti-inflam- matory effects comparable to the effect of hydrocortisone. ${ }^{120}$ For example, ciclopirox olamine has been shown to inhibit the effect of 5-lipoxygenase and cyclooxygenase in vitro. ${ }^{121}$

Topical corticosteroids: they may be used in the form of lotions, hair tonics, foams and shampoos. They result in a rapid improvement in symptoms (erythema, desquamation and pruritus); however, relapses are frequent. They should be used for the shortest time possible because of the side effects that occur with prolonged use.

Anti-inflammatory calcineurin inhibitors tacrolimus 0.03 and $0.1 \%$ and pimecrolimus $1 \%$. An alternative to topical corticosteroids, both tacrolimus and pimecrolimus exert an anti-inflammatory effect on SD that is equal to or superior to that of low-potency topical corticosteroids without the side effects of the latter. They can be used once or twice a day. ${ }^{122-124}$ They are well tolerated and may be used for resistant forms of SD of the face. ${ }^{125-6}$ They also induce a more prolonged remission than that achieved with topical corticosteroids. ${ }^{127}$

Other therapeutic options reported in the literature include: metronidazole $1 \%$ gel commonly used for the treatment of rosacea; twice daily use of tacalcitol (1,24-(R)- dihydroxyvitamin D3) cream, a medication used for the treatment of psoriasis; topical lithium succinate, which has an anti-inflammatory effect; benzoyl peroxide, a bactericide used for the treatment of inflammatory acne. ${ }^{128-131}$

Orally administered drugs may also be used, principally in cases of extensive SD and cases refractory to topical medication. The antifungal agents used and their respective doses are: ${ }^{132}$

. Ketoconazole $200 \mathrm{mg} / \mathrm{day}$ for 14 days

Itraconazole $100 \mathrm{mg} /$ day for 21 days

Terbinafine $250 \mathrm{mg} /$ day for 4 weeks

Some years ago, the use of oral isotretinoin was defended as a regulator of seborrhea and for this reason its use was suggested for the control of SD. The study carried out used very low doses of the drug (2.5 $\mathrm{mg}$, three times weekly and up to $5 \mathrm{mg}$ /day) with good efficacy. ${ }^{133}$ Recently, a case of sebaceous hyperplasia was reported in which response to isotretinoin was good. ${ }^{134}$ Scientific studies on the use of isotretinoin for seborrheic dermatitis are becoming steadily rarer, with the last having been published in 2003. ${ }^{133}$ Furthermore, there has been a report on the appearance of an eruption on the face similar to SD in individuals in use of this medication for the treatment of acne. ${ }^{135}$ 


\section{REFERENCES}

1. Schechtman RC, Midgley G, Hay RJ. HIV disease and Malassezia yeasts: a quantitative study of patients presenting with seborrhoeic dermatitis. $\mathrm{Br} J$ Dermatol. 1995;133:694-8.

2. Gupta AK, Madzia SE, Batra R. Etiology and management of Seborrheic dermatitis. Dermatology. 2004;208:89-93.

3. Inamadar AC PA. The genus Malassezia and human disease. Indian J Dermatol Venereol Leprol. 2003;69:265-70.

4. Moore M. Dermatite seborreica: cultivo do organismo caudador da dermatite produzida experimentalmente. An Bras Dermatol. 1936;11:7-10.

5. Unna P. Das seborrhoische Ekzem. Monatsschr Prakt Dermatol. 1897;6:827-46.

6. Leone R. [Presence and significance of Pityrosporon ovale in pityriasis of the scalp, in figured seborrheic eczema and in various squamous dermatoses. Note III. Cultural, biological and biochemical properties of Pityrosporon ovale, with special reference to the affinity for lipidic substances.]. Minerva Dermatol. 1952;27:123-7.

7. Leone R. [Presence and significance of Pityrosporon ovale in pityriasis of the scalp, in figured seborrheic eczema and in various squamous dermatoses. Note I. Quantitative research on the presence of Pityrosporon ovale in pityriasis of the scalp, in figured seborrheic eczema and in various squamous dermatoses.]. Minerva Dermatol. 1952;27:93-9.

8. Palacky AF, Strycek R. [Modifications in blood proteins in erythroderma and seborrhoeic dermatitis and their relation to biotin deficiency]. Pediatr Listy.1950;5:270-3.

9. Gougerot H, Grupper C, Plas G. [Cutaneous-mucosal ariboflavinosis; rosacea of cornea and medio-facial seborrheic dermatitis.]. Bull Soc Fr Dermatol Syphiligr. 1950:57:277-80.

10. Andrews GC, Post CF, Domonkos AN. Seborrheic dermatitis; supplemental treatment with vitamin B12. N Y State J Med. 1950;50:1921-5.

11. Kiessling $W$. [Clinical results with internal and intramuscular administration of biotin]. Dermatol Wochenschr. 1951;124:1246-9

12. Treger J, Moys A, Muzikova M. [Effect of intracutaneous biotin in eczema seborrhoeicum]. Bratisl Lek Listy. 1951;31:562-8.

13. Avcin M. [Dermatitis seborrheica and biotin deficiency in infants]. Zdrav Vestn.1952;21:15-21.

14. Schreiner AW, Rockwell E, Vilter RW. A local defect in the metabolism of pyridoxine in the skin of person with seborrheic dermatitis of the "sicca" type. J Invest Dermatol. 1952;19:95-6.

15. Nisenson A. Seborrheic dermatitis of infants and Leiners's disease: a biotin deficiency. J Pediatr. 1957;51:537-48.

16. Nisenson A, Barness LA. Treatment of seborrheic dermatitis with biotin and vitamin B complex. J Pediatr. 1972;81:630-1.

17. Schwartz RA, Janusz CA, Janniger CK. Seborrheic dermatitis: an overview. Am Fam Physician. 2006;74:125-30

18. Sudan BJ. Nicotine skin patch treatment and adverse reactions: skin irritation, skin sensitization, and nicotine as a hapten. J Clin Psychopharmacol. 1995;15:145-6.

19. Sudan BJ. Abrogation of facial seborrhoeic dermatitis with homoeopathic high dilutions of tobacco: a new visible model for Benveniste's theory of 'Memory of water'. Med Hypotheses. 1993;41:440-4.

20. Sudan BJ. Ketoconazole, leukotrienes, Paf-acether and nicotine as a hapten: the possible aetiology of seborrhoeic dermatitis. Med Hypotheses. 1987;23:33-8.

21. Sudan BJ. Seborrhoeic dermatitis induced by nicotine of horsetails (Equisetum arvense L.). Contact Dermatitis. 1985;13:201-2

22. Sudan BJ, Brouillard C, Sterboul J, Sainte-Laudy J. Nicotine as a hapten in seborrhoeic dermatitis. Contact Dermatitis. 1984;11:196-7.

23. Stone 0J. Seborrheic dermatitis--hyperreactive inflammation to saprophytes. Dermatol Int. 1968;7:14-6.

24. Mastrolonardo M, Diaferio A, Logroscino G. Seborrheic dermatitis, increased sebum excretion, and Parkinson's disease: a survey of (im)possible links. Med Hypotheses. 2003:60:907-11.

25. Pierard GE. Seborrheic dermatitis today, gone tomorrow? The link between the biocene and treatment. Dermatology. 2003;206:187-8.

26. Parish LC. L-dopa for seborrheic dermatitis. N Engl J Med. 1970;283:879.

27. Appenzeller 0, Harville D. Effect of L-dopa on seborrhea of Parkinsonism. Lancet. 1970;2:311-2.

28. Burton JL, Shuster S. Effect of L-dopa on seborrhoea of Parkinsonism. Lancet. 1970:2:311.

29. Burton JL, Shuster S. Effect of L-dopa on seborrhoea of parkinsonism. Lancet. 1970;2:19-20.

30. Potter J, Wyburn-Mason R. Effect of L-dopa on seborrhoea of parkinsonism. Lancet. 1970;2:660.

31. Wyburn-Mason R. Effect of L-dopa on seborrhoea of parkinsonism. Lancet. 1970;2:154.

32. Martignoni E, Godi L, Pacchetti C, Berardesca E, Vignoli GP, Albani G, et al. Is seborrhea a sign of autonomic impairment in Parkinson's disease? J Neural Transm. 1997;104:1295-304.

33. Binder RL, Jonelis FJ. Seborrheic dermatitis in neuroleptic-induced parkinsonism. Arch Dermatol. 1983;119:473-5.

34. Binder RL, Jonelis FJ. Seborrheic dermatitis: a newly reported side effect of neuroleptics. J Clin Psychiatry. 1984;45:125-6.

35. Moris G, Ribacoba R, Solar DN, Vidal JA. SUNCT syndrome and seborrheic dermatitis associated with craneosynostosis. Cephalalgia. 2001;21:157-9

36. Rocha N, Velho G, Horta M, Martins A, Massa A. Cutaneous manifestations of familial amyloidotic polyneuropathy. J Eur Acad Dermatol Venereol. 2005;19:605-7.

37. Rubin-Asher D, Zeilig G, Klieger M, Adunsky A, Weingarden H. Dermatologica findings following acute traumatic spinal cord injury. Spinal Cord. 2005:43:175-8.

38. Tronnier H. [On an unilaterally localized seborrhoic eczema in syringomyelia.]. Z Haut Geschlechtskr. 1964;37:207-17.

39. Bettley FR, Marten RH. Unilateral seborrheic dermatitis following a nerve lesion. AMA Arch Derm. 1956:73:110-5.

40. Chen TM, Fitzpatrick JE. Unilateral seborrheic dermatitis after decompression of Chiari I malformation and syringomyelia J Am Acad Dermatol. 2006;55:356-7.

41. Ercis M, Balci S, Atakan N. Dermatological manifestations of 71 Down syndrome children admitted to a clinical genetics unit. Clin Genet. 1996;50:317-20.

42. Daneshpazhooh M, Nazemi TM, Bigdeloo L, Yoosefi M. Mucocutaneous findings in 100 children with Down syndrome. Pediatr Dermatol. 2007;24:317-20.

43. Tager A, Berlin C, Schen RJ. Seborrhoeic Dermatitis in Acute Cardiac Disease. Br J Dermatol. 1964;76:367-9

44. Barba A, Piubello W, Vantini I, Caliari S, Cocchetto $R$, Vallaperta $P$, et al. Skin lesions in chronic alcoholic pancreatitis. Dermatologica. 1982;164:322-6.

45. Rao GS. Cutaneous changes in chronic alcoholics. Indian J Dermatol Venereol Leprol. 2004;70:79-81.

46. Naegeli B. [A case from practice (218). Alcoholic sensorimotor polyneuropathy and myopathy in chronic alcoholism. Seborrheic dermatitis]. Schweiz Rundsch Med Prax. 1991;80:650-2

47. Parish LC, Fine E. Alcoholism and skin disease. Int J Dermatol. 1985;24:300-1.

48. Moore M, Kile RL. Pityrosporum ovalis as a causative agent of seborrheic dermatitis Science. 1935;81:277-8.

49. Aspiroz MC, Moreno LA, Rubio MC. [Taxonomy of Malassezia furfur: state of the art] Rev Iberoam Micol. 1997:14:147-9.

50. Guého E MG, Guillot J. The genus Malassezia with description of four new species Antonie Van Leeuwenhoek. 1996:69:337-55.

51. Goodfield MJ, Saihan EM, Crowley J. Experimental folliculitis with Pityrosporum orbiculare: the influence of host response. Acta Derm Venereol. 1987;67:445-7.

52. Faergemann J. Pityrosporum infections. J Am Acad Dermatol. 1994;31:S18-20.

53. Faergemann J. Pityrosporum ovale and skin diseases. Keio J Med. 1993;42:91-4.

54. Terui T, Kudo K, Tagami $\mathrm{H}$. [Cutaneous immune and inflammatory reactions to Malassezia furfur]. Nihon Ishinkin Gakkai Zasshi. 1999;40:63-7.

55. Faergemann J, Fredriksson T. Tinea versicolor with regard to seborrheic dermatitis. An epidemiological investigation. Arch Dermatol. 1979;115:966-8.

56. McGinley KJ, Leyden JJ, Marples RR, Kligman AM. Quantitative microbiology of the scalp in non-dandruff, dandruff, and seborrheic dermatitis. J Invest Dermatol. 1975:64:401-5.

57. Faergemann J. Tinea versicolor and Pityrosporum orbiculare: mycological investigations, experimental infections and epidemiological surveys. Acta Derm Venereo Suppl (Stockh). 1979:1-23.

58. Bergbrant IM, Faergemann J. Seborrhoeic dermatitis and Pityrosporum ovale: a cultural and immunological study. Acta Derm Venereol. 1989;69:332-5.

59. Bourlond A, Votion V, Armijo F, Minne G. [Pityrosporum ovale in keratotic lesions of seborrheic areas]. Ann Dermatol Venereol. 1984;111:1081-5.

60. Nakabayashi A, Sei Y, Guillot J. Identification of Malassezia species isolated from patients with seborrhoeic dermatitis, atopic dermatitis, pityriasis versicolor and normal subjects. Med Mycol. 2000;38:337-41.

61. Nakabayashi A. [Identification of causative species in malassezia-associated dermatoses]. Nihon Ishinkin Gakkai Zasshi. 2002;43:65-8.

62. Rendic E, Diaz C, Fich F. [Characterization of species of the gender Malassezia in patients with seborrheic dermatitis and subjects without skin lesions]. Rev Med Chil. 2003;131:1295-300.

63. Gupta AK, Kohli Y, Summerbell RC, Faergemann J. Quantitative culture of Malassezia species from different body sites of individuals with or without dermatoses. Med Mycol. 2001;39:243-51.

64. Gaitanis G, Velegraki A, Alexopoulos EC, Chasapi V, Tsigonia A, Katsambas A. Distribution of Malassezia species in pityriasis versicolor and seborrhoeic dermatitis in Greece. Typing of the major pityriasis versicolor isolate M. globosa. Br J Dermatol. 2006;154:854-9

65. Tajima M, Sugita T, Nishikawa A, Tsuboi R. Molecular analysis of Malassezia 
microflora in seborrheic dermatitis patients: comparison with other diseases and healthy subjects. J Invest Dermatol. 2008;128:345-51.

66. Nakabayashi A, Sei Y. [Relationship between Malassezia Yeast and Infantile Seborrhoeic Dermatitis]. Nihon Ishinkin Gakkai Zasshi. 2001;42:218-20.

67. Bergbrant IM. Seborrhoeic dermatitis and Pityrosporum ovale: cultural, immunological and clinical studies. Acta Derm Venereol Suppl (Stockh). 1991;167:1-36.

68. Bergbrant IM, Faergemann J. The role of Pityrosporum ovale in seborrheic dermatitis Semin Dermatol. 1990;9:262-8.

69. Plotkin LI, Squiquera L, Mathov I, Galimberti R, Leoni J. Characterization of the lipase activity of Malassezia furfur. J Med Vet Mycol. 1996;34:43-8.

70. DeAngelis YM, Saunders CW, Johnstone KR, Reeder NL, Coleman CG, Kaczvinsky JR $\mathrm{Jr}$, et al. Isolation and expression of a Malassezia globosa lipase gene, LIP1. J Invest Dermatol. 2007;127:2138-46.

71. Ro BI, Dawson TL. The role of sebaceous gland activity and scalp microfloral metabolism in the etiology of seborrheic dermatitis and dandruff. J Investig Dermatol Symp Proc. 2005;10:194-7.

72. Bergbrant IM. Seborrhoeic dermatitis and Pityrosporum yeasts. Curr Top Med Mycol. 1995;6:95-112.

73. Cowley NC, Farr PM, Shuster S. The permissive effect of sebum in seborrhoeic dermatitis: an explanation of the rash in neurological disorders. $\mathrm{Br} \mathrm{J}$ Dermatol. 1990;122:71-6.

74. Wishner AJ, Teplitz ED, Goodman DS. Pityrosporum, ketoconazole, and seborrheic dermatitis. J Am Acad Dermatol. 1987;17:140-1.

75. Hay RJ, Graham-Brown RA. Dandruff and seborrhoeic dermatitis: causes and management. Clin Exp Dermatol. 1997;22:3-6.

76. Dawson TL Jr. Malassezia globosa and restricta: breakthrough understanding of the etiology and treatment of dandruff and seborrheic dermatitis through whole-genome analysis. J Investig Dermatol Symp Proc. 2007;12:15-9.

77. Braun-Falco 0, Heilgemeir GP, Lincke-Plewig H. [Histological differential diagnosis of psoriasis vulgaris and seborrheic eczema of the scalp]. Hautarzt. 1979;30:478-83.

78. Houck G, Saeed S, Stevens GL, Morgan MB. Eczema and the spongiotic dermatoses: a histologic and pathogenic update. Semin Cutan Med Surg. 2004;23:39-45.

79. Faergemann J. Pityrosporum yeasts--what's new? Mycoses. 1997;40 Suppl 1:29-32.

80. Faergemann J, Bergbrant IM, Dohse M, Scott A, Westgate G. Seborrhoeic dermatitis and Pityrosporum (Malassezia) folliculitis: characterization of inflammatory cells and mediators in the skin by immunohistochemistry. Br J Dermatol. 2001;144:549-56.

81. Parry ME, Sharpe GR. Seborrhoeic dermatitis is not caused by an altered immune response to Malassezia yeast. Br J Dermatol. 1998;139:254-63.

82. Ashbee HR, Fruin A, Holland KT, Cunliffe WJ, Ingham E. Humoral immunity to Malassezia furfur serovars $A, B$ and $C$ in patients with pityriasis versicolor, seborrheic dermatitis and controls. Exp Dermatol. 1994;3:227-33.

83. Neuber K, Kroger S, Gruseck E, Abeck D, Ring J. Effects of Pityrosporum ovale on proliferation, immunoglobulin (IgA, G, M) synthesis and cytokine (IL-2, IL-10, IFN gamma) production of peripheral blood mononuclear cells from patients with seborrhoeic dermatitis. Arch Dermatol Res.1996;288:532-6.

84. Watanabe S, Kano R, Sato H, Nakamura Y, Hasegawa A. The effects of Malassezia yeasts on cytokine production by human keratinocytes. J Invest Dermatol. 2001;116:769-73.

85. Ashbee HR, Ingham E, Holland KT, Cunliffe WJ. Cell-mediated immune responses to Malassezia furfur serovars $A, B$ and $C$ in patients with pityriasis versicolor, seborrheic dermatitis and controls. Exp Dermatol. 1994;3:106-12.

86. Passi S, Morrone A, De Luca C, Picardo M, Ippolito F. Blood levels of vitamin E, polyunsaturated fatty acids of phospholipids, lipoperoxides and glutathione peroxidase in patients affected with seborrheic dermatitis. J Dermatol Sci. 1991;2:171-8.

87. Ianosi S, Stoicescu I, Ianosi G, Neagoe D, Georgescu CV. The study of CD20 and CD45.Ro antibodies in the inflammatory infiltrate involved in acne and seborrheic dermatitis. Rom J Morphol Embryol. 2007;48:285-9.

88. Tsuji K, Nose Y, Ito M, Ozala A, Matsuo I. HLA antigens and susceptibility to psoriasis vulgaris in a non-Caucasian population. Tissue antigens. 1976;8:29-33.

89. Fritsch PO, Reider N. Other Eczematous Eruptions. In: Bolognia JL, Jorizzo JL, Rapini RP, editors. Dermatology. Spain: Mosby Elsevier; 2008. p.197-200.

90. Foley P, Zuo Y, Plunkett A, Merlin K, Marks R. The frequency of common skin conditions in preschool-aged children in Australia: seborrheic dermatitis and pityriasis capitis (cradle cap). Arch Dermatol.. 2003;139:318-22.

91. Misery L, Touboul S, Vincot C, Dutray S, Rolland-Jacob G, Consoli SG, et al. [Stress and seborrheic dermatitis]. Ann Dermatol Venereol. 2007;134:833-7.

92. Peyri J, Lleonart M. [Clinical and therapeutic profile and quality of life of patients with seborrheic dermatitis]. Actas Dermosifiliogr. 2007;98:476-82.

93. Sarkar R, Sharma RC, Koranne RV, Sardana K. Erythroderma in children: a clinicoetiological study. J Dermatol.. 1999;26:507-11.

94. Sarkar R, Garg VK. Erythroderma in children. Indian J Dermatol Venereol Leprol. 2010;76:341-7.
95. Al-Dhalimi MA. Neonatal and infantile erythroderma: a clinical and follow-up study of 42 cases. J Dermatol. 2007;34:302-7.

96. Cherny S, Mraz S, Su L, Harvell J, Kohler S. Heteroduplex analysis of T-cell receptor gamma gene rearrangement as an adjuvant diagnostic tool in skin biopsies for ery throderma. J Cutan Pathol. 2001;28:351-5.

97. Yamamoto T, Tsuboi R. Interleukin-2-induced seborrhoeic dermatitis-like eruption. J Eur Acad Dermatol Venereol. 2008;22:244-5.

98. Valia RG. Etiopathogenesis of seborrheic dermatitis. Indian J Dermatol Venereol Leprol. 2006;72:253-5.

99. Berger RS, Stoner MF, Hobbs ER, Hayes TJ, Boswell RN. Cutaneous manifestations of early human immunodeficiency virus exposure. J Am Acad Dermatol. 1988;19:298-303.

100. Eisenstat BA, Wormser GP. Seborrheic dermatitis and butterfly rash in AIDS. N Engl J Med. 1984;311:189.

101. Soeprono FF, Schinella RA, Cockerell CJ, Comite SL. Seborrheic-like dermatitis of acquired immunodeficiency syndrome. A clinicopathologic study. J Am Acad Dermatol. 1986;14:242-8.

102. Blanes M BI, Merino E, Portilla J, Sánchez-Payá J, Betlloch I. Current prevalence and characteristics of dermatoses associated with human immunodeficiency virus infection. Actas Dermosifiliogr. 2010;101:702-9.

103. Hakansson C, Faergemann J, Lowhagen GB. Studies on the lipophilic yeast Pityrosporum ovale in HIV-seropositive and HIV-seronegative homosexual men. Acta Derm Venereol. 1988;68:422-6.

104. Schoefer H, Sachs DL, Ochsendorf F. HIV- associated skin and mucocutaneous dis eases. In: Hoffman C, Rockstroh JK, Kamps BS, editors. HIV medicine. 15th ed. Paris, Cagliari, Wuppertal: Flying Publisher: 2007. p.596.

105. Rincón S, Celis A, Sopó L, Motta A, Cepero de García MC. Malassezia yeast species isolated from patients with dermatologic lesions. Biomedica. 2005;25:189-95.

106. Vidal C, Girard PM, Dompmartin D, Bosson JL, Mettra C, Groslambert P, et al. Seborrheic dermatitis and HIV infection. Qualitative analysis of skin surface lipids in men seropositive and seronegative for HIV. J Am Acad Dermatol. 1990;23:1106-10.

107. Passi S, Picardo M, Morrone A, De Luca C, Ippolito F. Skin surface lipids in HIV seropositive and HIV sero-negative patients affected with seborrheic dermatitis. J Dermatol Sci. 1991;2:84-91.

108. Nnoruka EN, Chukwuka JC, Anisuiba B. Correlation of mucocutaneous manifestations of HIV/AIDS infection with CD4 counts and disease progression. Int J Dermatol. 2007;46 Suppl 2:14-8.

109. Dunic I, Vesic S, Jevtovic DJ. Oral candidiasis and seborrheic dermatitis in HIV-infected patients on highly active antiretroviral therapy. HIV Med. 2004;5:50-4.

110. Hardcastle NJ, Tunbridge AJ, Shum KW, Dockrell DH, Green ST. Alopecia in association with severe seborrhoeic dermatitis following combination antiretroviral therapy for acute retroviral syndrome. J Eur Acad Dermatol Venereol. 2005;19:631-3.

111. Smith K, Kuhn L, Coovadia A, Meyers T, Hu CC, Reitz C, et al. Immune reconstitution inflammatory syndrome among HIV-infected South African infants initiating antiretroviral therapy. AIDS. 2009;23:1097-107.

112. Schaub NA, Drewe J, Sponagel L, Gilli L, Courvoisier S, Gyr N, et al. Is there a relation between risk groups or initial CD4 T cell counts and prevalence of seborrheic dermatitis in HIV-infected patients? Dermatology.1999;198:126-9.

113. Prose NS. Cutaneous manifestations of HIV infection in children. Dermatol Clin. 1991;9:543-50.

114. Dann FJ, Tabibian P. Cutaneous diseases in immunodeficiency vírus-infected patients referred to the UCLA Immunossupression skin Clinic: reasons for referral and management of select diseases. Cutis. 1995;55:85-8.

115. Wiwanitkit V. Prevalence of dermatological disorders in Thai HIV-infected patients correlated with different CD4 lymphocyte count statuses: a note on 120 cases. Int J Dermatol. 2004;43:265-8.

116. Elewski B. Safe and effective treatment of seborrheic dermatitis. Cutis. 2009;83:333-8.

117. Satchell AC, Saurajen A, Bell C, Barnetson RS. Treatment of dandruff with $5 \%$ tea tree oil shampoo. J Am Acad Dermatol. 2002;47:852-5.

118. Wolwerton SE, editor. Compreensive dermatologic drug therapy. 2nd ed. Philadelphia: Saunders Elsevier; 2007. p.720-3.

119. Wilson J. Hormônios adrenocorticotrófico, esteróides adrenocorticais e seus análogos sintéticos; inibidores da síntese e das ações dos hormônios adrenocorticais In: Hardman JG, Limbird LE, editores. As bases farmacológicas da terapêutica. 9. ed. México-DF: Mc Graw Hill; 1996. p.1099.

120. Faergemann J. Treatment of seborrhoeic dermatitis of the scalp with ketoconazole shampoo. A double-blind study. Acta Derm Venereol. 1990;70:171-2.

121. Hanel H, Smith-Kurtz E, Pastowsky S. [Therapy of seborrheic eczema with an anti fungal agent with an antiphlogistic effect]. Mycoses. 1991;34 Suppl 1:91-3.

122. Reitamo S, Ortonne JP, Sand C, Cambazard F, Bieber T, Fölster-Holst R, et al. A multicentre, randomized, double-blind, controlled study of long-term treatment with $0,1 \%$ tacrolimus ointment in adults with moderate to severe atopic dermatitis. $\mathrm{Br} \mathrm{J}$ Dermatol. 2005;152:1282-9. 
123. Rigopoulos D, loannides D, Kalogeromitros D, Gregoriou S, Katsambas A Pimecrolimus cream $1 \%$ vs. betamethasone 17 -valerate $0.1 \%$ cream in the treatment of seborrhoeic dermatitis. A randomized open-label clinical trial. $\mathrm{Br} \mathrm{J}$ Dermatol. 2004;151:1071-5.

124. Cicek D, Kandi B, Bakar S, Turgut D. Pimecrolimus 1\% cream, methylprednisolone aceponate $0.1 \%$ cream and metronidazole $0.75 \%$ gel in the treatment of seborrhoeic dermatitis: a randomized clinical study. J Dermatolog Treat. 2009;20:344-9.

125. Warshaw EM, Wohlhuter RJ, Liu A, Zeller SA, Wenner RA, Bowers S, et al. Results of a randomized double-blind, vehicle-controlled efficacy trial of pimecrolimus cream $1 \%$ for the treatment of moderate to severe facial seborrheic dermatitis. J Am Acad Dermatol. 2007;57:267-64.

126. Ozden MG, Tekin NS, Itter N, Ankarali H. Topical pimecrolimus $1 \%$ for resistent seborrheic dermatitis of the face: an open-label study. Am J Clin Dermatol. 2010;11: 51-4.

127. Shin H, Kwon OS, Won CH, Kim BJ, Lee YW, Choe YB, et al. Clinical efficacies of topical agents for the treatment of seborrheic dermatitis of the scalp: a comparative study. J Dermatol. 2009;36:131-7.
128. Parsad D, Pandhi R, Negi KS, Kumar B. Topical metronidazole in seborrheic dermatitis-a double-blind study. Dermatology. 2001;202:35-7.

129. Nakayama J. Four cases of sebopsoriasis or seborrheic dermatitis of the face and scalp successfully treated with 1a-24 (R)-dihydroxycholecalciferol (tacalcitol) cream. Eur J Dermatol. 2000;10:528-32.

130. Boyle J, Burton JL, Faergemann J. Use of topical lithium succinate for seborrhoeic dermatitis. Br Med J (Clin Res Ed). 1986;292:28.

131. Bonnetblanc JM, De Prost Y, Bazex J, Maignan-Gayrard P. [Treatment of seborrheic dermatitis with benzoyl peroxide]. Ann Dermatol Venereol. 1990;117:123-5.

132. Scaparro E, Quadri G, Virno G, Orifici C, Milani M. Evaluation of the efficacy and tolerability of oral terbinafine (Daskil) in patients with seborrhoeic dermatitis. A multicentre, randomized, investigator-blinded, placebo-controlled trial. $\mathrm{Br} \mathrm{J}$ Dermatol. $2001 \mathrm{Apr} ; 144(4): 854-7$.

133.Geissler SE, Michelsen S, Plewig G. Very low dose isotretinoin is effective in controlling seborrhea. J Dtsch Dermatol Ges. 2003;1:952-8.

134. Yu C SM, Stevens G, Liskanich R, Horowitz D. Isotretinoin as monotherapy for sebaceous hyperplasia. J Drugs Dermatol. 2010;9:699-701.

135. Barzilai A, David M, Trau H, Hodak E. Seborrheic dermatitis-like eruption in patients taking isotretinoin therapy for acne: retrospective study of five patients. Am J Clin Dermatol. 2008;9:255-61.

How to cite this article/Como citar este artigo: Sampaio ALB, Mameri A, Jeunon T, Ramos-e-Silva M, Nunes AP, Carneiro S. Dermatite seborreica. An Bras Dermatol. 2011;86(6):1061-74. 


\section{QUESTÕES}

\section{1- It is incorrect to affirm:}

a) there are forms of seborrheic dermatitis (SD) on dry skin, therefore there is no association of this disorder with sebaceous glands.

b) seborrheic dermatitis is characterized by presenting lesions in areas that are rich in sebaceous glands, such as: scalp, face, ears, presternal region and folds (intertriginous areas).

c) the association of this illness with sex hormones is due to the fact that seborrheic dermatitis occurs in newborns and improves with time, relapsing in adolescence

d) adults may present lesions on the face, scalp, trunk and folds that exacerbate after stressful periods and/or sleep deprivation

\section{2- Differential diagnoses of seborrheic dermatitis,} except for:
a) psoriasis
b) Langerhans cells histiocytosis
c) parapsoriasis
d) atopic dermatitis

\section{3- As regards the epidemiology of seborrheic der-} matitis:

a) it affects adults, starting at the age of 40

b) it has two incidence peaks: on newborns and from 40 years of age onwards

c) the prevalence of the disease is higher among HIV-positive patients and their lesions are more intense

d) it affects both genders equally and there is no difference between races

\section{4- It is incorrect to affirm:}

a) as a rule, there is association of seborrheic dermatitis with vitamin deficiency

b) neurological diseases predispose to the onset of seborrheic dermatitis

c) systemic diseases such as alcoholism, acute myocardial infarction and pancreatitis of alcoholic etiology present greater incidence of seborrheic dermatitis

d) Parkinson's disease patients being treated with levodopa show improvement of seborrheic dermatitis
5- Diseases directly or indirectly associated with Malassezia sp., except for:

a) hidrosadenitis

b) confluent and reticulated dermatosis of Gourgerot and Carteaud

c) pityriasis versicolor

d) peritonitis in individuals subjected to peritoneal dialysis at the outpatient clinic

6- As regards the immunology of seborrheic dermatitis:

a) all Malassezia species stimulate production of a determined profile of inflammatory interleukins, leading to the onset of seborrheic dermatitis

b) there is evidence that in seborrheic dermatitis there is alteration of humoral immunity, with the presence of circulating antibodies to the fungus

c) increased anti-Malassezia antibody production in patients with SD, as observed in atopic dermatitis

d) no increased anti-Malassezia antibody production was found in patients with seborrheic dermatitis; this was significantly observed in patients with atopic dermatitis. This fact suggests that there is no anti-Malassezia sp. immune response in seborrheic dermatitis.

\section{7- In cases of adult seborrheic dermatitis:}

a) there always is intense pruritus

b) it may be limited to small body areas or be generalized, with erythroderma

c) lesions are limited to the scalp and face

d) in skinfolds, when lesions acquire a humid, macerated appearance, there is infection by Candida sp.

8- As regards the physiopathogenesis of seborrheic dermatitis:

a) the Malassezia sp. fungus is found on the skin accidentally, there is no association with seborrheic dermatitis

b) the Malassezia $s p$. fungus triggers seborrheic dermatitis by means of pathogenic substance production, toxic to the individual

c) the onset of seborrheic dermatitis depends on three factors: sebum production, Malassezia metabolism and individual susceptibility

d) there is no evidence of association of the disease with heredity 
9- Concerning seborrheic dermatitis in childhood, the statements below are correct, except for:

a) it is similar to atopic dermatitis, both by the affected locations and the presence of pruritus

b) diaper rash or contact dermatitis spares the folds, while SD predominates in them

c) psoriasis in childhood is very similar to SD in this age group; it is almost impossible to distinguish them

d) it is characterized by yellowish desquamative lesions adherent to the scalp, the face and skinfolds: retroauricular, neck, axillae and inguinal region

10- The treatment of seborrheic dermatitis prescribes the measures below, except for:
a) inflammation control
b) removal of crusts with exfoliation
c) suppression of Malassezia sp. proliferation
d) skin oiliness control

11- Concerning the use of corticosteroids in the treatment of seborrheic dermatitis, the statements below are correct, except for:

a) the chronic use of topical corticosteroids is prescribed to avoid recidivism of the illness

b) the use of corticosteroids is generally topical, in the form of shampoos, hair solutions, lotions, creams or salves

c) the use of topical corticosteroids should be limited to periods of exacerbation and its discontinuance is mandatory, as soon as possible

d) other options to topical corticosteroids are topical antifungals and topical calcineurin inhibitors

12- As regards the shampoos used in the treatment of seborrheic dermatitis, the statements below are correct, except for:

a) those that have an antiproliferative effect reduce cellular division in the epidermis, diminishing scale formation

b) examples of shampoos with antiproliferative effect: those with a coal tar base and their derivatives, selenium sulfide, zinc pyrithione and clobetasol.

c) the antifungal shampoos are those with ketoconazole and ciclopirox, as well as selenium sulfide and zinc pyrithione

d) keratolytic shampoos are those with a salicylic acid base, with or without sulfur
13- In order to control seborrheic dermatitis, it is necessary to maintain areas rich in sebaceous glands under oiliness control. All OF the statements below are correct, except for:

a) oral isotretinoin in low doses has been increasingly used for this purpose, due to its low rate of collateral effects in a low-severity disease

b) some of the patients need anti-inflammatory medication chronically, in addition to antiproliferative and keratolytic substances

c) the use of antiproliferative soaps and/or shampoos, in most cases, is sufficient to control the disease

d) oral isotretinoin in low doses has been increasingly less used in scientific studies on seborrheic dermatitis treatment

\section{4- Mark the incorrect statement:}

a) seborrheic dermatitis affects $10 \%$ of the Brazilian population

b) HIV-positive patients have a greater prevalence of the disease, which is more intense and tend to be refractory to treatment

c) it can affect newborns, adolescents and adults

d)the disease incidence peak occurs between 40 and 60 years of age

\section{5- Mark the correct statement:}

a) Malassez, in 1874, observed the fungus on the skin of all individuals

b) Moore and Kile related the fungus directly to seborrheic dermatitis

c) Leone, in 1952, discarded the relationship between the fungus and other diseases

d) Leone also discarded the association of the fungus with seborrheic dermatitis

16- Concerning the clinical presentation of seborrheic dermatitis:

a) in childhood, the disease is represented by yellowish desquamative lesions adherent to the scalp

b) the childhood form improves after the age of 5

c) the adult seborrheic dermatitis form presents as light to moderate erythema of nasolabial folds, to papulous, exudative and/or desquamative lesions of variable extension on the face, scalp, trunk and folds

d) there are no reports of factors that contribute to the improvement or exacerbation of lesions, both in adults and in children 
17- There are disagreements regarding the species found in seborrheic dermatitis lesions. Which is the incorrect statement below:

a) Nakabayashi et al. reported having found similar quantities of $M$. furfur and $M$. globosa in individuals with seborrheic dermatitis

b) Rendic et al. reported more M. globosa than M. furfur and M. sympodialis

c) Gupta and Gaitanis reported a greater quantity of M. globosa

d) Tajima also found a greater quantity of M. globosa

18- There is no association of the disease with:
a) seasonality
b) heredity
c) mental stress
d) increased T-cell function

19- It is incorrect to affirm:

a) Bergbrant and Faergman, in 1989, found a greater quantity of Malassezia sp. In the skin of individuals with seborrheic dermatitis

b) the maintenance of residual sebum deposits (as with inadequate hygiene) may predispose to the onset of the disease

c) Vidal et al. described how the lipid profiles of the skin of individuals with AIDS is different from those without AIDS, but did not determine its relationship with the development of SD

d) as it is a lipophilic fingus, skin sebum allows the growth of Malassezia sp. and consequently the development of SD
20- Concerning the histopathology of seborrheic dermatitis, it is wrong to affirm:

a) there is inflammatory infiltrate composed mainly of lymphocytes and histiocytes, spongiosis and slight to moderate psoriasiform hyperplasia, as well as parakeratosis around follicular ostia (shoulder parakeratosis)

b) during the chronic phase, in addition to findings of the acute phase, there is marked psoriasiform hyperplasia with dilatation of capillaries and small veins of the superficial plexus

c) seborrheic dermatitis in HIV-positive individuals with shows the same histopathological characteristics of those who are not HIV-positive

d) histopathological findings of psoriasis vulgaris are similar, except for the absence of spongiosis

\section{Answers}

Understanding HIV-associated facial lipoatrophy: from the beginning to the present. An Bras Dermatol. 2011;86(5):843-64.

\begin{tabular}{c|l|ll}
\hline $1 d$ & $6 c$ & $11 d$ & $16 c$ \\
$2 b$ & $7 d$ & $12 d$ & $17 d$ \\
$3 c$ & $8 c$ & $13 b$ & $18 c$ \\
$4 a$ & $9 d$ & $14 b$ & $19 b$ \\
$5 b$ & $10 d$ & $15 d$ & $20 d$
\end{tabular}

\section{Papers}

Information for all members: The EMCD questionnaire is now available at the homepage of the Brazilian Annals of Dermatology: www.anaisdedermatologia.org.br. The deadline for completing the questionnaire is 60 days from the date of online publication. 